\section{Mobilität, relative elektrophoretische}

R. Westermeier

Freising, Deutschland

Englischer Begriff relative electrophoretic mobility

Definition Größe zur Beschreibung der Beweglichkeit eines Partikels oder Moleküls im elektrischen Feld, die sich auf die Wanderungsgeschwindigkeit einer Markersubstanz bezieht.

Beschreibung Für Proteine lässt man meist Bromphenolblau mit der Probe mitlaufen, für Nukleinsäuren ebenfalls Bromphenolblau oder das langsamer wandernde Xylencyanol. In der Praxis setzt man die Distanz zwischen Probenauf- gabe und der Position der Molekülbande in Relation zur Distanz zwischen Probenaufgabe und Markerbande. Da die Markersubstanzen stark geladene niedermolekulare Farbstoffe sind, wandern sie schneller als die Probensubstanzen. Die relative elektrophoretische Mobilität besitzt stets einen Wert, der $<1$ ist.

Die relative elektrophoretische Mobilität ist abhängig von der Nettoladung des Moleküls und der Größe des Moleküls. Strukturproteine haben bei gleicher Molekularmasse größere Ausdehnung als globuläre Proteine. In einem nichtrestriktiven Medium wie offenen Kapillaren, großporigen Agarosegelen (s. - Agarosegelelektrophorese) und Celluloseacetatfolien (s. $>$ Celluloseacetatfolien-Elektrophorese) ist die relative Mobilität von Proteinen ausschließlich von der Nettoladung abhängig. 